\title{
Bacterial skin and soft tissue infections
}

\section{SUMMARY}

Bacterial skin infections are common presentations to both general practice and the emergency department.

The optimal treatment for purulent infections such as boils and carbuncles is incision and drainage. Antibiotic therapy is not usually required.

Most uncomplicated bacterial skin infections that require antibiotics need 5-10 days of treatment.

There is a high prevalence of purulent skin infections caused by community-acquired (non-multiresistant) methicillin-resistant Staphylococcus aureus. It is therefore important to provide adequate antimicrobial coverage for these infections in empiric antibiotic regimens.

\section{Introduction}

It is important to have a good understanding of the common clinical manifestations and pathogens involved in bacterial skin infections to be able to manage them appropriately. The type of skin infection depends on the depth and the skin compartment involved. The classification and management of these infections are outlined in Table 1.

\section{Impetigo}

Impetigo is a superficial bacterial infection that can develop either through direct invasion of normal skin (primary) or infection at sites of damaged skin (secondary) (Fig. 1). It is common in children and is highly contagious. There are two forms:

- non-bullous or crusted impetigo - distinct yellow, crusting lesions that may be itchy. Typically involves face or extremities

- bullous impetigo - usually caused by Staphylococcus aureus. Presents as bullae that rupture to form a brown crust.

\section{Boils and carbuncles}

Boils and carbuncles are associated with infection of a hair follicle and extend into subcutaneous tissue. They are tender and painful but the patient is usually systemically well. In most cases, lesions can be treated with incision and drainage alone. Antibiotic therapy is only required if there is spreading cellulitis or systemic infection.

\section{Folliculitis}

This usually presents as a crop of pustules affecting areas of moist skin with hair. It is most commonly caused by $S$. aureus but can also be linked to other organisms like Pseudomonas aeruginosa when associated with specific exposures like hot tubs and spas.

\section{Cellulitis and erysipelas}

Both cellulitis and erysipelas manifest as spreading areas of skin erythema and warmth. Localised infections are often accompanied by lymphangitis and lymphadenopathy. Not infrequently, groin pain and tenderness due to inguinal lymphadenitis will precede the cellulitis. Some patients can be quite unwell with fevers and features of systemic toxicity. Bacteraemia, although uncommon (less than $5 \%$ ), still occurs.

Erysipelas involves the upper dermis and superficial lymphatics. Skin lesions are usually raised with a clear demarcation of infected skin. Classically, erysipelas affects the face (Fig. 2), but it can also involve other areas such as the lower limb. It is most commonly caused by Streptococcus pyogenes (group A streptococcus).

Cellulitis extends further into the deep dermis and subcutaneous tissue. It commonly involves the lower

\section{Fig. 1 Impetigo}

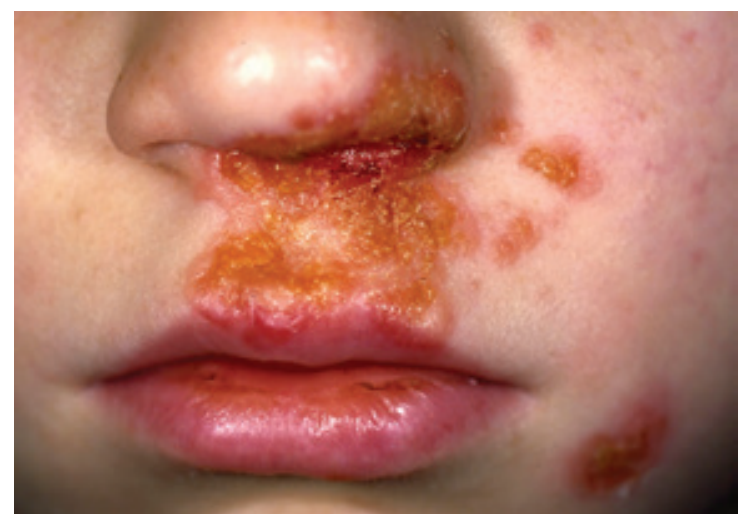

Source: (c) Professor Raimo Suhonen, used with permission from DermNet NZ
Vichitra Sukumaran

Advanced traineel

Sanjaya Senanayake

Senior specialist

Associate professor of medicine ${ }^{2}$

'Infectious Diseases

Canberra Hospital

${ }^{2}$ Australian National

University Medical School

Canberra

\section{Keywords}

antibiotics, cellulitis, impetigo, soft tissue infection

Aust Prescr 2016;39:159-63 http://dx.doi.org/10.18773/ austprescr.2016.058 


\section{Table 1 Therapeutic approach to common bacterial skin infections}

\begin{tabular}{|c|c|c|}
\hline Infection & Likely pathogens & Management \\
\hline Impetigo & $\begin{array}{l}\text { Staphylococcus aureus } \\
\text { Streptococcus pyogenes }\end{array}$ & $\begin{array}{l}\text { Mild or localised disease: } \\
\text { - wash crusts } \\
\text { - topical mupirocin } \\
\text { Multiple lesions or recurrent disease: } \\
\text { - cultures to guide treatment } \\
\text { - } \quad \text { oral antibiotics (dicloxacillin/cephalexin/trimethoprim plus sulfamethoxazole) for up to } 10 \text { days } \\
\text { - intravenous antibiotics if no improvement } \\
\text { - for recurrent infection due to S. aureus consider decolonisation } \\
\text { Advice and education of household members to reduce transmission: } \\
\text { - avoid contact with lesions } \\
\text { - wash hands regularly, particularly after touching lesions }\end{array}$ \\
\hline $\begin{array}{l}\text { Boils and } \\
\text { carbuncles }\end{array}$ & $\begin{array}{l}\text { S. aureus } \\
\text { S. pyogenes }\end{array}$ & $\begin{array}{l}\text { Incision and drainage most important step in management: } \\
\text { - culture and susceptibility testing for lesions } \\
\text { - antibiotics if spreading cellulitis or systemic symptoms } \\
\text { - oral dicloxacillin/cephalexin for } 5 \text { days } \\
\text { - oral clindamycin, or trimethoprim plus sulfamethoxazole for community-acquired-MRSA for } 5 \text { days }\end{array}$ \\
\hline Folliculitis & $\begin{array}{l}\text { S. aureus } \\
\text { S. pyogenes } \\
\text { Pseudomonas aeruginosa }\end{array}$ & $\begin{array}{l}\text { Treatment usually supportive } \\
\text { Warm compresses or topical mupirocin } \\
\text { In severe infection treat as per impetigo }\end{array}$ \\
\hline $\begin{array}{l}\text { Cellulitis and } \\
\text { erysipelas }\end{array}$ & $\begin{array}{l}\text { S. aureus } \\
\text { Beta-haemolytic streptococci }\end{array}$ & $\begin{array}{l}\text { Examine for predisposing factors } \\
\text { Consider unusual exposures (see Table 2) - broaden antibiotic therapy if this is the case } \\
\text { Culture and susceptibility testing for lesions, tissue or blood } \\
\text { Elevate limb } \\
\text { Treat underlying predisposing skin infection e.g. tinea } \\
\text { Mild disease: } \\
\text { - oral dicloxacillin/cephalexin/clindamycin for 5-10 days } \\
\text { - oral phenoxymethylpenicillin if culture is positive or clinical presentation of S. pyogenes } \\
\text { Severe disease or systemic features: } \\
\text { - intravenous flucloxacillin/cephazolin/vancomycin } \\
\text { Consider decolonisation or prophylactic antibiotics with recurrent disease }\end{array}$ \\
\hline
\end{tabular}

\section{Periorbital S. aureus}

cellulitis

\section{Streptococcus species}

Haemophilus influenzae type b (in unvaccinated patients)

\section{Mild disease:}

- oral dicloxacillin/cephalexin/clindamycin for 7 days

If suspect $H$. influenzae type b infection (unvaccinated, < 5yrs old):

- oral amoxycillin plus clavulanate, or cefuroxime for 7 days

Severe disease or systemic features:

- treat as orbital cellulitis

\section{Orbital S. aureus}

cellulitis

\section{Streptococcus species}

H. influenzae type b

(in unvaccinated patients)

Anaerobic bacteria

fasciitis

S. aureus

S. pyogenes

Gram negatives, Clostridium species

Anaerobic bacteria

Inpatient hospital management with urgent surgical opinion

Blood cultures and CT scan of orbits

Intravenous antibiotics

Inpatient hospital management with urgent surgical debridement

Culture and susceptibility testing of tissue

Broad-spectrum intravenous antibiotics including clindamycin (antitoxin effect by suppressing synthesis of bacterial endotoxins) 


\section{Fig. 2 Erysipelas}

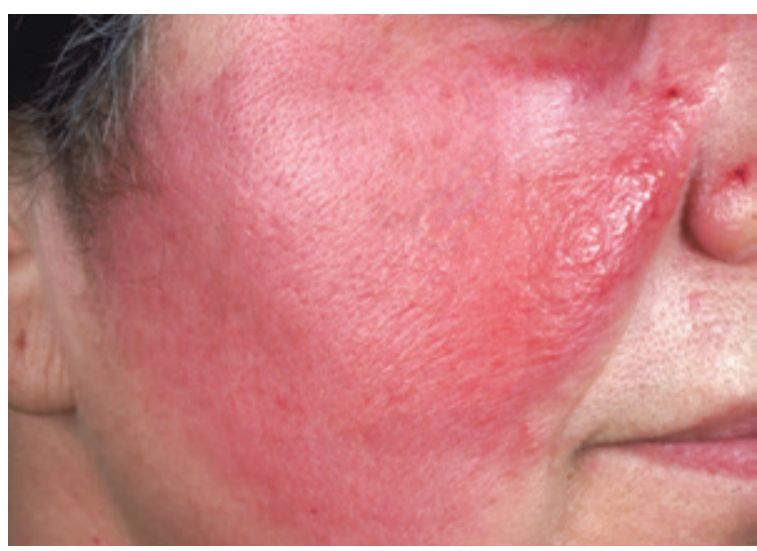

Image appears with permission from VisualDx.

limbs (Fig. 3) and in most cases is unilateral. Bilateral lower limb cellulitis is exceedingly rare and usually reflects stasis dermatitis and does not require antibiotic treatment. Other areas of the body such as the eye and the abdominal wall can also be affected. Periorbital cellulitis involves the eyelids and does not extend into the bony orbit. Orbital cellulitis is a much more serious infection with deeper extension and impairment of vision and extraocular eye movements, often with pain.

Cellulitis is usually caused by either $S$. aureus or beta-haemolytic streptococci (groups A, B, C or G). Differentiating between these two organisms can help guide therapy. Streptococcal infection is usually characterised by acute onset of rapidly spreading erythema, lymphangitis and lymphadenopathy. Staphylococcal cellulitis is usually associated with purulent lesions with erythema. Cultures from wounds or blood can further help delineate the causative organism. In the absence of positive cultures however, it can be difficult to discriminate between the two and antibiotic therapy to cover both organisms (for example flucloxacillin, dicloxacillin, cephalexin, clindamycin) is often used.

\section{Diagnostic approach to cellulitis}

When evaluating a patient with cellulitis, review systemic features. Potential portals of entry for infection should also be looked for. These include:

- disruption to the skin barrier, insect bites, wounds, abrasions

- $\quad$ pre-existing skin infection, tinea pedis, impetigo

- underlying skin disease, eczema, psoriasis

- Iymphoedema or surgical disruption of the lymphatic or venous system

- peripheral vascular disease with impaired arterial supply

- chronic venous insufficiency.

\section{Fig. 3 Cellulitis}

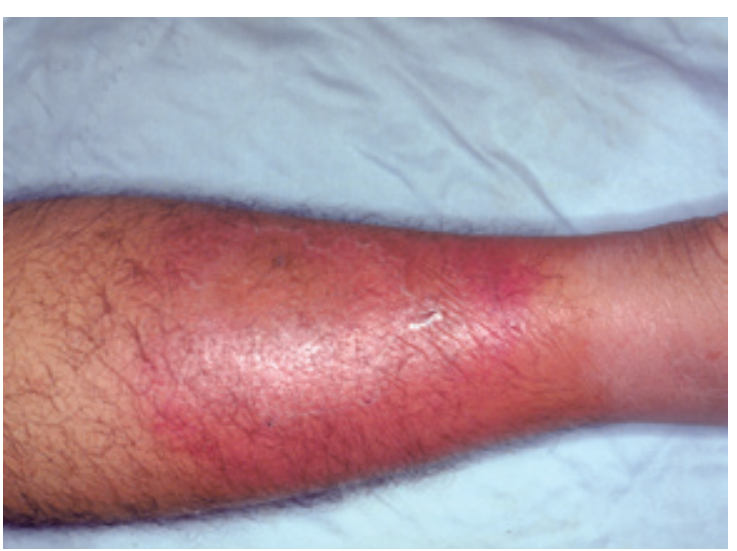

Image appears with permission from VisualDx.

It is important to consider less common causes of skin infection associated with specific clinical circumstances or exposures (Table 2). In these cases, specimens should be collected for culture and sensitivity testing and treatment regimens broadened to cover likely pathogens. In difficultto-treat or atypical infections, specialist opinion is recommended.

\section{Table 2 Skin infections associated with unusual exposures and clinical scenarios}

\begin{tabular}{|c|c|}
\hline Exposure history & Associated organisms \\
\hline Freshwater exposure & Aeromonas hydrophila \\
\hline Saltwater exposure & $\begin{array}{l}\text { Vibrio species especially } \\
\text { V. vulnificus }\end{array}$ \\
\hline $\begin{array}{l}\text { Other aquatic } \\
\text { infections }\end{array}$ & $\begin{array}{l}\text { Mycobacterium marinum, } \\
\text { Erysipelothrix rhusiopathiae }\end{array}$ \\
\hline Soil or thorn injuries & $\begin{array}{l}\text { Atypical mycobacteria, nocardia, } \\
\text { fungi, Sporothrix schenkii }\end{array}$ \\
\hline Cat bites & Pasteurella multocida \\
\hline Dog bites & $\begin{array}{l}\text { Capnocytophaga canimorsus, } \\
\text { Pasteurella canis }\end{array}$ \\
\hline Human bites & Eikenella corrodens \\
\hline Hot tub exposure & Pseudomonas aeruginosa \\
\hline $\begin{array}{l}\text { Immunosuppression } \\
\text { or neutropenia }\end{array}$ & $\begin{array}{l}\text { Pseudomonas aeruginosa, } \\
\text { Cryptococcus species, nocardia, } \\
\text { mycobacteria }\end{array}$ \\
\hline
\end{tabular}


Many conditions may masquerade as cellulitis (see Box 1). These conditions should always be considered in atypical cases to avoid the unnecessary use of antibiotics.

\section{Necrotising skin infections}

Necrotising skin infections, the best known of which is necrotising fasciitis, are a medical and surgical emergency that require prompt debridement and appropriate intravenous antibiotics. Infections can be caused by single or multiple pathogens (e.g. S. pyogenes, Gram negatives, Clostridium). Infection usually involves the necrosis of underlying soft tissues or muscle. Typical early clinical features are induration and erythema of the affected area with pain out of proportion to overlying skin changes. As infection progresses, the skin can change colour to purple or blue and eventually breaks down to form bullae and gangrene (Fig. 4). The patient is usually quite unwell with systemic toxicity, haemodynamic instability and multi-organ failure. Urgent hospital referral is essential in all cases. Surgical exploration is the only way to establish the diagnosis of necrotising fasciitis and is also the definitive management in all cases. Exploration also allows material to be obtained for appropriate cultures to guide antibiotic therapy.

\section{Box 1 Non-infectious differential diagnosis for cellulitis}

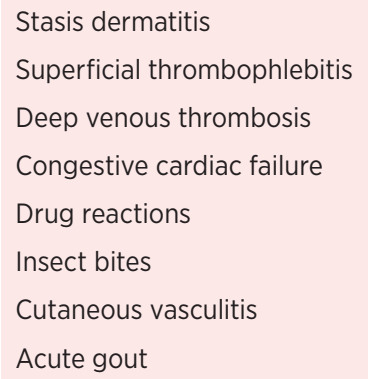

\section{Fig. 4 Necrotising fasciitis}

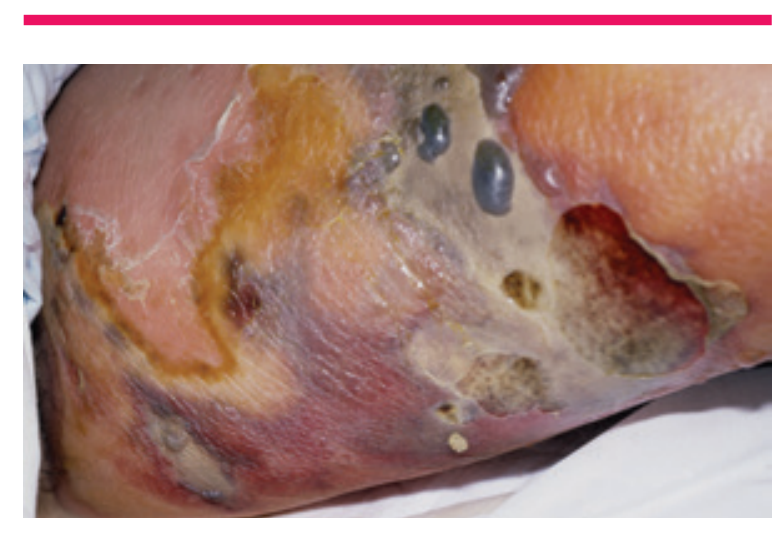

Image appears with permission from VisualDx.

\section{Methicillin-resistant Staphylococcus aureus (MRSA)}

There has been a rapid increase in the rates of community-associated multiresistant MRSA skin infections in Australia ${ }^{1,2}$ and worldwide. It is important to consider the possibility of this pathogen if contemplating empirical antibiotic therapy for bacterial skin infections (clindamycin or trimethoprim plus sulfamethoxazole). Culture and susceptibility testing of lesions should be used to guide therapy as community-associated MRSA is resistant to betalactam antibiotics such as flucloxacillin, dicloxacillin and the cephalosporins.

\section{When to use topical antibiotics}

According to current recommendations, topical mupirocin is only recommended in cases of mild impetigo and folliculitis. All other infections should be managed with either incision and drainage or oral and intravenous antibiotics. Topical fusidic acid monotherapy has been associated with increased fusidic acid resistance ${ }^{3,4}$ among strains of $S$. aureus and it is not our preference to use this on its own.

\section{When to use oral antibiotics}

Patients with no signs of systemic toxicity and uncontrolled comorbidities can usually be managed with oral antibiotics as outpatients.

\section{When to consider hospital referral and intravenous antibiotics}

Patients with severe disease who are systemically unwell will require assessment in hospital for monitoring and intravenous antibiotics. Parenteral antibiotics can either be administered as an inpatient or through an Outpatient Parenteral Antibiotic Treatment or Hospital in the Home program. Factors that would favour hospital management of cellulitis include: 5

- comorbid conditions (renal impairment, diabetes, congestive cardiac failure, splenectomy) or immunosuppression

- rapidly progressive infection

- concern for deep space infection (presence of bullae, necrosis or muscle involvement)

- high fevers and rigors

- haemodynamic instability

- suppurative wound or bite (especially on face or hand) requiring surgical drainage

- lack of systemic or local response to oral antibiotics, or rising or unchanging $\mathrm{C}$-reactive protein concentrations despite adequate therapy

- positive blood cultures

- inability to tolerate or absorb oral antibiotics. 


\section{How to manage recurrent skin infections}

Recurrent cellulitis is extremely challenging. Each repeated episode of cellulitis can cause inflammation and disruption of the lymphatic system and subsequent lymphoedema. The affected limb is subsequently more prone to infection and a vicious cycle of cellulitis and limb swelling is established.

Treating the underlying cause of infection is the most important step in management. In cases of chronic lymphoedema and venous stasis, compression of the affected limb by bandaging or stockings helps to increase venous return and contractility of the lymphatic ducts, therefore decreasing swelling and cellulitis. Further supportive measures such as elevation of the limb may also confer symptomatic relief. For example in cellulitis of the leg, raising the foot higher than the hip with supportive cushions helps to reduce swelling and pain. Prophylactic long-term suppressive antibiotics offer symptomatic benefit and cost-benefit in cases of recurrent streptococcal cellulitis., ${ }^{6,7}$ Options include twice-daily oral penicillin or cephalexin.

For recurrent staphylococcal infections, decolonisation measures should be considered (Box 2). ${ }^{8}$ In difficult cases of recurrent infections despite prophylactic antibiotics, expert consultation with an infectious disease specialist is recommended.

\section{Conclusion}

Bacterial skin infections have a variety of presentations from localised, trivial infection to rapidly progressive infection with systemic toxicity and considerable mortality. It is important to be able to recognise and treat these infections in the community, and in cases of severe infection to refer the patient promptly for specialist care. $<$

Conflict of interest: none declared
SELF-TEST QUESTIONS

True or false?

3. Topical mupirocin is the first-line treatment for multiple impetigo lesions.

4. Erysipelas is most commonly caused by Streptococcus pyogenes.

Answers on page 185

\section{Box 2 Suggested decolonisation regimen for recurrent boils or staphylococcal skin infections ${ }^{8}$}

Treat acute lesions.

Collect nasal or perineal swabs to determine antibiotic susceptibility of Staphylococcus aureus.

Once active skin lesions resolve, eradicate staphylococcal carriage with

mupirocin nasal ointment for 5 days

PLUS EITHER

chlorhexidine $2 \%$ or triclosan $1 \%$ wash for 5 days in showers

OR

sodium hypochlorite solution ( $60 \mathrm{~mL}$ of $6 \%$ solution per bathtub) or triclosan $2 \%$ bath oil for 5 days in baths

Do not share towels. Wash bed linen (at least weekly) and towels (after each use) in hot water and hang out to dry in the sun.

Decolonisation of household contacts is not recommended unless the measures outlined fail to prevent recurrence in the index case or contacts have a history of recurrent skin infection.

If decolonisation measures fail, repeat topical regimen together with

oral rifampicin for 7 days

PLUS

oral dicloxacillin, fusidate sodium or trimethoprim plus sulfamethoxazole depending on susceptibility of the organism.

\section{REFERENCES}

1. Gosbell IB, Mercer JL, Neville SA, Crone SA, Chant KG, Jalaludin BB, et al. Non-multiresistant and multiresistant methicillin-resistant Staphylococcus aureus in community-acquired infections. Med J Aust 2001;174:627-30.

2. Bennett CM, Coombs GW, Wood GM, Howden BP, Johnson LE, White D, et al. Community-onset Staphylococcus aureus infections presenting to general practices in South-eastern Australia. Epidemiol Infect 2014;142:501-11. http://dx.doi.org/10.1017/S0950268813001581

3. Howden BP, Grayson ML. Dumb and dumber--the potential waste of a useful antistaphylococcal agent: emerging fusidic acid resistance in Staphylococcus aureus. Clin Infect Dis 2006;42:394-400. http://dx.doi.org/10.1086/499365

4. Williamson DA, Monecke S, Heffernan H, Ritchie SR, Roberts SA, Upton A et al. High usage of topical fusidic acid and rapid clonal expansion of fusidic acid-resistant Staphylococcus aureus: a cautionary tale. Clin Infect Dis 2014:59:1451-4. http://dx.doi.org/10.1093/cid/ciu658
5. Gottlieb T, Atkins BL, Shaw DR. 7: Soft tissue, bone and joint infections. Med J Aust 2002;176:609-15.

6. Thomas KS, Crook AM, Nunn AJ, Foster KA, Mason JM, Chalmers JR, et al.; U.K. Dermatology Clinical Trials Network's PATCH I Trial Team. Penicillin to prevent recurrent leg cellulitis. N Engl J Med 2013;368:1695-703. http://dx.doi.org/10.1056/NEJMoa1206300

7. Mason JM, Thomas KS, Crook AM, Foster KA, Chalmers JR, Nunn AJ, et al. Prophylactic antibiotics to prevent cellulitis of the leg: economic analysis of the PATCH I \& II trials. PLoS One 2014;9:e82694. http://dx.doi.org/10.1371/ journal.pone.0082694

8. Recurrent staphylococcal skin infection [2014 Nov]. In: eTG complete. [Internet]. Melbourne: Therapeutic Guidelines Limited; 2016. www.tg.org.au [cited 2016 Sep 1]

\section{FURTHER READING}

Stevens DL, Bisno AL, Chambers HF, Dellinger EP, Goldstein EJ, Gorbach SL, et al.; Infectious Diseases Society of America. Practice guidelines for the diagnosis and management of skin and soft tissue infections: 2014 update by the Infectious
Diseases Society of America. Clin Infect Dis 2014;59:e10-52. http://dx.doi.org/ $10.1093 /$ cid/ciu296 